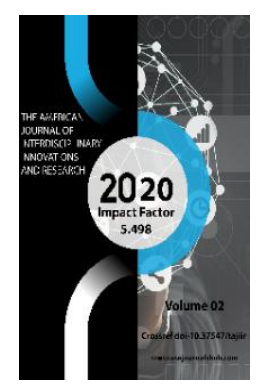

\title{
History, Structure And Types Of Microprocessors
}

Hakimov Zohid Abdullayevich

Assistant Department of "Information Technology" Urgench branch of Tashkent University of Information Technologies, Uzbekistan

Journal Website:

http://usajournalshub.c

om/index,php/tajiir

Copyright: Original content from this work may be used under the terms of the creative commons attributes 4.0 licence.

\section{ABSTRACT}

This article gives you a brief overview on microprocessor types, performance, and computer hardware. The article also provides basic concepts about Microprocessors. Learn about microprocessor types, Intel, Intel Celeron, VIA, NVIDIA, Elbrus, Philips, Hitachi, Sun, AMD Athlon and more. You will learn about the functional parts of the microprocessor, the block diagram of the microprocessor, the command register of the microprocessor.

\section{KEYWORDS}

Computer and technology, Microprocessor, Intel, Pentium, Pentium Pro, Pentium II, PentiumllI, Intanium 2 McKinely.

\section{INTRODUCTION}

As the first President of the Republic of Uzbekistan Islam Karimov noted, "XXI century is the century of information technologies", world development is rapidly developing along with information technologies. Especially in fifteen to twenty years, technology has evolved rapidly. Modern information and communication media have a 
permanent place in our lives. The potential of computer technology has increased several times. The capabilities of mobile devices, optical devices, global Internet technologies can hardly be overestimated. It is important to note that cutting edge technology has embraced all aspects of community life. Computers and technology have become an integral part of human life, and computer devices and equipment are evolving from year to year. Examples include a microprocessor, a system unit, RAM, and so on.

A microprocessor (also known as a CPU) is a CPU. The processor mainly consists of the following devices:

- Microprocessor - controls the computer and performs all calculations.

- $\quad$ The microprocessor has the ability to perform various operations quickly. Its speed can be 100 million operations per second and more.

- Random access memory stores programs and data required by the processor.

- When the computer is turned off, the data in RAM is erased.

- $\quad$ The hard disk always stores software and data.

- Electronic circuits (or controllers) control the operation of various devices that enter the computer (monitors, keyboards, etc.).

- Communicates with the processor through the I/ O port.

- $\quad$ There are special ports and common ports for data exchange with internal devices.
- A printer, "mouse" can be connected to common ports.

There are 2 types of common ports: parallel - LPT1 - LPT4 and serial - COM1 - COM3. Parallel ports perform I / O faster than serial ports. A central processing unit (CPU) is an important part of every computer. The CPU sends signals to control the other parts of the computer, almost like how a brain controls a body. Microprocessors are classified into five types, namely: CISC-Complex Instruction Set Microprocessors, RISC-Reduced Instruction Set Microprocessor, ASIC-Application Specific Integrated Circuit, Superscalar Processors, DSP's-Digital Signal Microprocessors. Mikroprotsessor (MP). It is the central block on the $P C$, designed to control the work performed by all blocks of the machine, as well as to perform arithmetic and logic operations with information. The microprocessor consists of: control unit (CU) transmits the results of previous operations and certain control signals (control pulses) arising from the simultaneous execution of the operation to all machine blocks at the right time; generates addresses of memory slots used in work and transfers them to the corresponding blocks of the computer; this control device receives the main pulse train from the clock generator; arithmetic logic device (ALD) - designed to perform all arithmetic and logical operations with numerical and symbolic information (in some PC models, to speed up operations, an additional mathematical coprocessor is connected to the ALD); microprocessor memory (MPM) - machine work is used for short-term recording and display (transmission) of information used in accounting work performed on the air. This is 
because a main memory device (MMD) cannot always provide the speed of writing, searching, and computing the information needed for a fast microprocessor to work efficiently; registers - fast memory slots that can vary in length (different from MMD slots, where the standard length is 1 byte and the operating speed is much lower); microprocessor interface system - connects to other computer devices and provides communication; includes the internal interface of the MP and memory buffer registers, as well as input-output ports (ICPs) and the system bus control circuit; a set of tools designed to ensure effective collaboration. An I / O port is a connecting device that allows a microprocessor to connect another computer device.

\section{THE MAIN FINDINGS AND RESULTS}

Microprocessor, also known as CPU (MzP). The Central Processing Unit (CPU) is the main component of a computer that performs the arithmetic and logic operations provided by a program, controls the computation process, and coordinates the operation of all devices in the computer.

In November 1971, Intel announced the creation of the world's first 4004 microprocessor, developed by several companies and intended for commercial distribution. This microprocessor, which by today's standards is very simple, contains only 2,300 transistors and performs only 60,000 computational operations per second.

Today's microprocessors are highly complex mass-produced products containing over 5.5 million transistors and hundreds of millions of operations per second. Research in this area is gaining momentum. There are also many types of microprocessors. As an example, Intel microprocessors are given in this table (table 1). 
Table 1

Development of Intel Microprocessors: 1971 to 2012

\begin{tabular}{|c|c|c|c|c|c|}
\hline Manufacturer & Processor & $\begin{array}{l}\text { Date of } \\
\text { introduct } \\
\text { ion }\end{array}$ & $\begin{array}{l}\text { Number of } \\
\text { transistors }\end{array}$ & Process & $\begin{array}{l}\text { Area[m } \\
\left.\mathrm{m}^{2}\right]\end{array}$ \\
\hline \multirow{13}{*}{ Intel } & Intel4004 & 1971 & 2,300 & $10 \mu \mathrm{m}$ & 12 \\
\hline & Intel8008 & 1972 & 3,500 & $10 \mu \mathrm{m}$ & 14 \\
\hline & Intel8080 & 1974 & 4,400 & $6 \mu \mathrm{m}$ & 20 \\
\hline & Intel8085 & 1976 & 6,500 & $3 \mu \mathrm{m}$ & 20 \\
\hline & Intel8086 & 1978 & 29.000 & $3 \mu \mathrm{m}$ & 33 \\
\hline & Intel80286 & 1982 & 134,000 & $1.5 \mu \mathrm{m}$ & 44 \\
\hline & Intel80386 & 1985 & 275,000 & $1.5 \mu \mathrm{m}$ & 104 \\
\hline & Intel80486 & 1989 & $1,180,235$ & $1 \mu \mathrm{m}$ & 173 \\
\hline & Pentium & 1993 & $3,100,000$ & $1,8 \mu \mathrm{m}$ & 294 \\
\hline & Pentium Pro & 1995 & $5,500,000$ & $0,5 \mu \mathrm{m}$ & 307 \\
\hline & Pentium II & 1997 & $7,500,000$ & $\begin{array}{l}0,35 \\
\mu \mathrm{m}\end{array}$ & 195 \\
\hline & PentiumIII & 1999 & $9,500,000$ & $\begin{array}{l}0,25 \\
\mu \mathrm{m}\end{array}$ & 128 \\
\hline & Pentium4 & 2000 & $42,00,000$ & $180 \mathrm{~nm}$ & 217 \\
\hline
\end{tabular}




\begin{tabular}{|c|c|c|c|c|}
\hline $\begin{array}{ll}\text { Intanium } & 2 \\
\text { McKinely } & \end{array}$ & 2002 & $220,000,000$ & 180nm & 421 \\
\hline Core 2 Duo & 2006 & $291,000,000$ & $65 \mathrm{~nm}$ & 143 \\
\hline Core i7 (Quad) & 2008 & $731,000,000$ & $45 \mathrm{~nm}$ & 263 \\
\hline Six- Core Core i7 & 2010 & $1,170,000,000$ & $32 \mathrm{~nm}$ & 230 \\
\hline $\begin{array}{l}\text { Six- Core Core } \\
\text { i7/8-Core Xeon E5 }\end{array}$ & 2011 & $2,270,000,000$ & $32 \mathrm{~nm}$ & 434 \\
\hline $\begin{array}{l}\text { 8-CoreItanium } \\
\text { Poulson }\end{array}$ & 2012 & $3,100,000,000$ & $32 \mathrm{~nm}$ & 544 \\
\hline
\end{tabular}

The control device is the most functional device of a personal computer. It processes control signals sent to all units of the machine. Command register is a register where the command code is stored. Here is the address of the operation and operands to be performed. The command register is located in the interface part of the microprocessor. It is called the command register block. Operations decoder - this logical block selects the output path corresponding to the operation code coming from the command register. Permanent Firmware (PZU) - stores control signals in Google cells. These impulses control the processing of information that takes place in the blocks of the computer. The pulse operations correspond to the operation code selected by the decoder.
All microprocessors can be divided into 3 groups:

$>\mathrm{MP}$ with CISC type (Complex Instruction Set Command) complete set of command systems;

$>$ MP with abbreviated set of commands of RISC type (Redused Instruction Set Command);

$>$ MISC type (Minimum Instruction Set Command) with a minimum set of command systems and a sufficiently high speed MP (these models are currently under development).

The microprocessor's memory consists of high-speed registers with a discharge rate of at least one machine word. The number and size of registers vary from microprocessor to 
microprocessor, and microprocessor registers differ from general-purpose registers and special registers. Custom registers are used to store various addresses (for example, command addresses), tokens of operations performed, computer operating modes (for example, flag registers), and so on. General purpose registers are universal registers that can be used to store any information.

A CPU is a device that performs arithmetic and logic operations. It includes an arithmetic logic device and a control device. Typically, an MP consists of one or more microprocessors, ranging from 4 to 64 bits. In computers, the number of bits of the microprocessor plays an important role, and the more it is, the more powerful the computer. The number of discharges is the number of binary discharges that can be processed at one time. Currently, there are 4-, 8-, 16-, 32- 64-bit computers. Central processing unit (CPU, central computing device). In 1971, Intel produced the first microprocessor 4004 with 2250 transistors. A control device that performs arithmetic and logic operations. Each program consists of a sequence of commands. The processor executes these commands. Processors are built on very large integrated circuits. Processor speed is determined by the number of operations performed in 1 second and is measured in $\mathrm{Hz}$ (hertz). How many bits a processor can run at one time determines its discharge. 8, 16, 32, 64, 128 bit processors are widely used today [1.34].

Let's take a look at the first two versions of the Intel Microprocessor. The Intel 4004 is a 4bit microprocessor developed by Intel Corporation and released on November 15, 1971. This chip is considered the world's first commercially available single-chip microprocessor. (Figure 1)

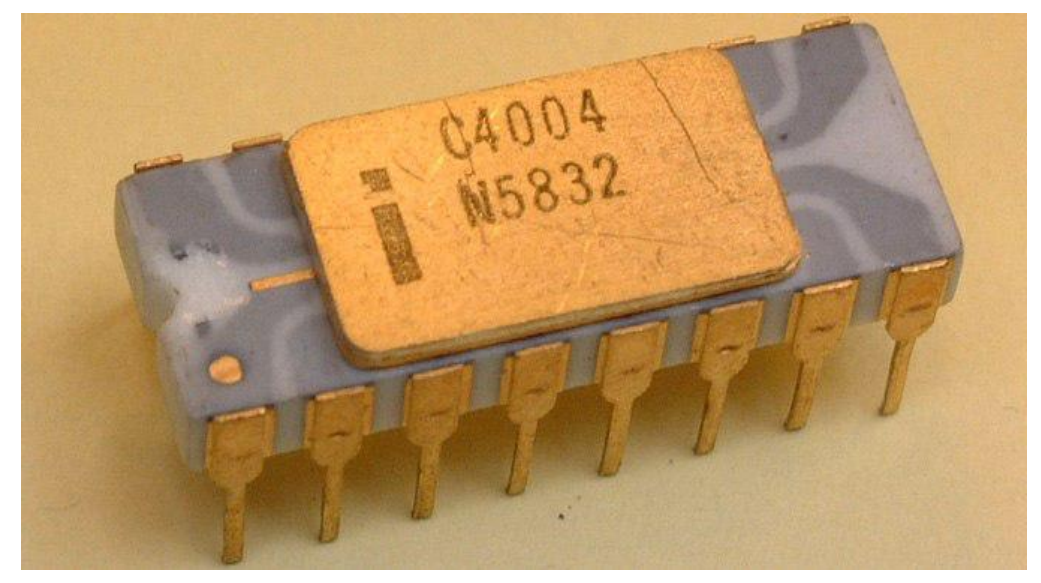

(Figure 1) Intel 4004 is a 4-bit microprocessor.

The Intel 8080 is an 8-bit microprocessor released by Intel in April 1974. It is an improved version of the Intel 8008 processor. Intel claims that this processor provides a tenfold increase in performance compared to the Intel 8008 microprocessor.( Figure 2) 


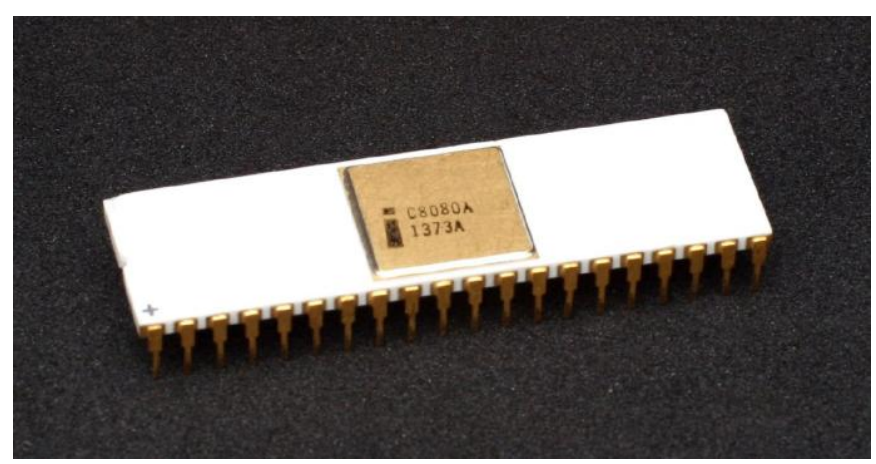

(Figure 2) Intel 8080 is an 8-bit microprocessor.

\section{CONCLUSION}

In conclusion, the 21st century is the age of modern technology, information and communication. Especially in fifteen to twenty years, technology has developed rapidly. Modern media and communication take a permanent place in our life. The potential of computer technology has increased several times. The capabilities of mobile devices, optical devices, global Internet technologies can hardly be overestimated. It is important to note that cutting edge technology has embraced all aspects of community life. As technology advances, so do its devices. A microprocessor is a device that performs the most basic functions in a computer. It's hard to imagine a computer without a microprocessor. It is divided into two types: microarchitecture and macroarchitecture. The microarchitecture consists of a microprocessor, a device that performs the above operations, that is, devices that add, multiply, reverse, and reverse signals. In the macroarchitecture, there are devices that transmit control signals to other devices, that is, in turn, set the mode of operation of other devices.

\section{REFERENCES}

1. Fundamentals of microprocessor and computer technology (textbook), Bukhara: 2016.

2. Mathivanan N. Microprocessors, Computer Hardware and Interfaces. Delhi: PHI Learning, 2003.

3. Ayala, Kennet J. 8051 mikrokontroller. Boston: Cengage, 2004.

4. Xuang, Xan-Way. PIC Microcontroller: Introduction to Software and Hardware Interface Boston: Cengage, 2005.

5. Rafiquzzaman Muhammad. System design based on microprocessors and microcomputers. Boca Raton: CRC Press, 1990.

6. Balashov E.P., Puzankov D.V Microprocessors and microprocessor systems. - M., 1981.

7. Korolev L.N. Microprocessors, microand mini-computers. Moscow: 1988.

8. Koledov L.A. Technology and designs of microcircuits, microprocessors and microassemblies. Moscow: Soviet radio, 1989 -p. 400 - 20,000

9. E. Klingman Designing microprocessor systems. Moscow: Mir, 1980 .-p. 576 
10. Ray A. K., Bhurchand K.M. Advanced

Microprocessors and Peripherals

(unspecified). India: 